\title{
CONDIÇÕES SOCIAIS E COMPETITIVIDADE
}

\author{
Mariano de Matos Macedo*
}

\section{INTRODUÇÃO}

Quando se procura entender as relações entre as condições sociais e a competitividade das nações é comum assumir que um maior esforço de crescimento econômico e de ganhos de competitividade pode ter, pelo menos no curto prazo, implicações relativamente perversas sobre as condições de vida de segmentos expressivos da população.

No passado, alguns analistas concluíram que existe, no curto prazo, uma relação inversa entre essas variáveis e afirmaram a necessidade de se fazer um trade-off entre o crescimento econômico e a disseminação massiva de melhores condições de vida em um país.

Não se está muito distante dos anos 70, em que era corrente proclamar a necessidade do "bolo crescer, para depois ser distribuído". Partia-se do princípio de que a distribuição da renda, concentrada nos segmentos de rendimentos mais elevados, favorecia o aumento da taxa de poupança e, portanto, uma maior taxa de crescimento econômico.

Ao contrário, caso a distribuição de renda fosse menos concentrada, a taxa de poupança e o investimento seriam menores, implicando em uma modesta taxa de crescimento. Dessa forma, "estar-se-ia sacrificando, portanto, uma expansão constante de bem estar no futuro em troca de uma ligeira melhora da situação presente para os setores mais pobres da população, o que representaria, segundo Mário Simonsen, uma verdadeira 'agiotagem contra as gerações futuras"," 1

* Doutor em Economia pelo IE-Unicamp, Professor do Departamento de Economia da UFPR e Gerente do Núcleo de Produtividade Sistêmica do IBQP-PR.

1 Cf. SERRA, J. A reconcentração da renda: justificações, explicações e dúvidas. In: TOLIPAN, R.; TINELLI, A. C. A controvérsia sobre distribuição de renda e desenvolvimento. Rio de Janeiro: Zahar, 1975. p. 264. 
Faz parte do debate da época em torno dessa questão o contra-argumento que sustentava que uma distribuição de renda menos concentrada poderia vir a favorecer uma maior taxa de crescimento. Partindo-se de Keynes ou Kalecki, afirmava-se que, em uma economia capitalista, o investimento não era determinado pela existência de poupanças previamente disponíveis, mas sim de acordo com as expectativas de sua rentabilidade vis a vis o custo de obter recursos para o seu financiamento (recursos próprios ou endividamento no sistema financeiro). Entendia-se que, no movimento da acumulação de capital, os níveis crescentes de investimentos determinariam níveis equivalentes de lucros e poupança, que acompanhariam, centeris paribus, o crescimento da renda. ${ }^{2} \mathrm{O}$ crescimento da renda seria maior quanto maior fosse o multiplicador dos investimentos, que, por sua vez, seria mais elevado no caso de uma alta propensão a consumir. Fechando o argumento, essa teoria explicava que uma alta propensão a consumir dependeria de uma melhor distribuição da renda.

A dicotomia em torno dessas posições vem se diluindo. Novos argumentos ou novos desenhos teóricos vêm procurando entender em que medida as precárias condições sociais vigentes em um determinado país contribuem para restringir o crescimento econômico, os ganhos de produtividade (PIB per capita) ${ }^{3}$ e seu potencial de competitividade.

Nesse sentido, pode-se recorrer a duas vertentes dos atuais rumos da teoria econômica: as proposições relativas ao conceito de competitividade sistêmica e à chamada "moderna teoria do desenvolvimento econômico".

O objetivo desse artigo é mostrar que, embora essas vertentes desenvolvam abordagens teóricas radicalmente distintas, chegam a conclusões muito semelhantes no sentido de afirmar que as precárias condições sociais ${ }^{4}$ de um país constituem entraves ao seu crescimento econômico e aos seus ganhos de produtividade e competitividade.

2 Conforme SERRA, op. cit., p. 268. Ver também TAUILE, J. R. Novos padrões tecnológicos, competitividade e bem-estar social: perspectivas brasileiras. Rio de Janeiro: IEI/ UFRJ, 1988. p. 25/32.

3 A taxa de crescimento do PIB per capita é um indicador genérico da produtividade do trabalho de um país e, portanto, ceteribus paribus, um dos determinantes de seu poder não espúrio de competitividade.

4 Entende-se por condições sociais as condições de vida da população (níveis educacionais e culturais, situação da saúde, padrões nutricionais, características da habitação etc.) que, de forma expressiva, podem ser sintetizadas pelo nível e grau de desigualdade da distribuição da renda gerada em uma sociedade. 


\section{CONCEITOS DE COMPETITIVIDADE SISTÊMICA}

Uma das versões mais difundidas do conceito de competitividade sistêmica emerge das recentes proposições da Cepal relativas à necessidade de um enfoque integrado entre transformação produtiva ${ }^{5}$ e eqüidade, com o objetivo de redefinir novos rumos para o desenvolvimento dos países latino-americanos, no contexto das atuais e profundas transformações tecnológicas, organizacionais, econômicas, financeiras e sociais que caracterizam o mundo contemporâneo.

O novo enfoque analítico da Cepal parte do princípio que os

[...] dados empíricos mais recentes não revelam a existência de nenhuma correlação geral e sistemática entre crescimento e distribuição de renda. Concretamente os dados mostram que: a) a desigualdade não aumenta em uma primeira fase do desenvolvimento para depois diminuir. Existem quase tantos países em desenvolvimento em que a desigualdade aumenta como países em que esta diminui; b) a desigualdade não tende a ser maior nos países em desenvolvimento mais pobres do que nos menos pobres; c) a desigualdade não tende a aumentar quanto mais rápido seja o crescimento econômico; e d) uma maior desigualdade inicial não induz a um maior crescimento econômico. ${ }^{6}$

Segundo a Cepal, essas constatações sugerem que "crescimento econômico e eqüidade podem ser objetivos não só em conflito (como correntemente são considerados), mas também podem chegar a serem complementares ou interdependentes"?

Dessa forma, a Cepal conclui que a relação precisa entre crescimento e eqüidade dependerá da orientação das políticas públicas, o que implica em "outorgar prioridades àquelas políticas que permitam que esses objetivos possam ser alcançados de forma simultânea ou complementar". ${ }^{8}$ Significa, por um lado, "[...] preferir aquelas políticas econômicas que favoreçam não só o crescimento, mas também a eqüidade e, por outro, destacar na política social os efeitos produtivos e de eficiência e não somente os de eqüidade". ${ }^{9}$

${ }^{5}$ Conforme FAJNZYLBER, F. Competitividad internacional: evolución y Lecciones. Revista de la CEPAL, Santiago, Chile, n. 36, dic. 1988; transformação produtiva é entendida como a necessidade de adpatação das economias latino-americanas frente aos novos desafios de competitividade colocados pelas transformações que vêm ocorrendo no mundo contemporâneo.

${ }^{6}$ Conforme CEPAL. Equidad y transformación productiva: un enfoque. Santiago, Chile: CEPAL, 1992. p. 16-17.

${ }^{7}$ Ibid. p. 17.
${ }^{8}$ Ibid. p. 17.
${ }_{9}^{9}$ Ibid. p. 16. 


\section{Para a Cepal,}

[...] salvo as políticas relativas às transferências de renda, como são, por exemplo, as relacionadas com a criação de empregos de emergência de baixa produtividade ou subsídios monetários ou não monetários às famílias pobres, a grande maioria das demais políticas são funcionais tanto para o crescimento como para a eqüidade. Assim ocorre, por exemplo, com certas políticas destinadas à criação de empregos produtivos, ou a freiar a sua queda, e com aquelas direcionadas ao investimento em capital humano. As maiores possibilidades de conflito podem ser encontradas entre aquelas políticas para as quais ambos os objetivos são complementares a longo prazo, mas conflitivos a curto prazo. Tal é o caso, por exemplo, da maioria das políticas de meio ambiente ou as de investimento em capital humano com longos períodos de maturação, como as de educação formal (ver quadro 1). ${ }^{10}$

Quadro 1 - COMPLEMENTARIEDADE E CONFLITO ENTRE POLÍTICAS DE CURTO E LONGO PRAZOREFERENTES AO CRESCIMENTO ECONÔMICO E À EQÜIDADE, SEGUNDO ACEPAL

\section{LONGO PRAZO}

Caráter das políticas

Complementar

\section{CURTO}

PRAZO
Conflito

Nessa perspectiva, o novo enfoque da Cepal se centra na integração sistêmica de três eixos: progresso técnico, geração de empregos produtivos e investimentos em recursos humanos.

10 Conforme CEPAL, op. cit., p. 17. 
Assim, para a Cepal, nas condições de geração de riquezas no mundo contemporâneo, não existem alternativas: os processos de transformação produtiva com eqüidade devem ser centrados na incorporação deliberada e sistemática de progresso técnico, visando crescentes níveis de produtividade e uma maior geração de empregos produtivos. ${ }^{11}$

Por sua vez, a incorporação e a difusão de progresso técnico requer uma infra-estrutura tecnológica adequada e a modernização de serviços básicos de apoio à produção, como são os serviços de transporte, dos portos, de comunicações, do comércio, de educação, de saúde e de previdência. O caráter sistêmico desse processo vincula a empresa a um conjunto de fatores econômicos e sociais que contribuem para a sua competitividade internacional.

A geração de empregos produtivos constitui o segundo eixo do novo enfoque cepalino, na medida em que é o principal mecanismo mediante o qual "as grandes maiorias podem contribuir para o desenvolvimento e participar de seus frutos", ${ }^{12}$ através de uma melhor distribuição renda, de um padrão de consumo mais elevado e de um maior e melhor acesso aos serviços de educação, saúde e previdência. Dado que a massa salarial (emprego x salário) depende do crescimento da produtividade total e esta da modernização tecnológica, esse enfoque considera que somente uma transformação produtiva dinâmica, sustentada pelo progresso técnico, será capaz de gerar uma expansão significativa e duradoura tanto do emprego quanto da massa salarial. E isso é fundamental porque não só amplia os mercados internos, possibilitando economias de escala e escopo, consideradas básicas para a expansão não espúria das exportações, mas também porque contribui para a coesão social que se faz necessária aos avanços dos processos de transformação produtiva e permite a formação de uma força de trabalho melhor qualificada, segundo os requisitos das condições atuais de competitividade.

A Cepal desconsidera a possibilidade de um conflito entre aumentos de produtividade, ${ }^{13}$ decorrentes da incorporação de progresso técnico, e a geração de empregos. Justifica essa posição da seguinte forma:

11 A Cepal descarta como ilusória qualquer possibilidade de um crescimento liderado pelo setor informal, ou seja, pela expansão de atividades que, em geral, possuem baixos níveis de produtividade. Continua a entender que a expansão da massa salarial desse setor depende fundamentalmente do crescimento das atividades formais (emprego produtivo) que, por sua vez, está atrelado ao dinamismo do processo de incorporação e difusão do progresso técnico. Conforme CEPAL, op. cit., p. 18.

12 CEPAL, op. cit., p. 18.

$13 \mathrm{O}$ conceito de produtividade aqui adotado se refere a um nível maior de produto por trabalhador. 
[...] este aparente conflito entre produtividade e emprego tem origem em conceitos equivocados sobre a eficiência e produtividade. $\mathrm{Na}$ realidade, a eficiência econômica se refere ao uso que se faz de todos os fatores de produção e não somente da mão-de-obra. Como a mudança tecnológica não tende a induzir somente a um uso menos intensivo de mão-de-obra, mas também o de capital, uma tecnologia que gere um maior nível de emprego por unidade de produto e que, portanto, apareça como menos produtiva, pode ser economicamente a mais eficiente e de maior produtividade total se permitir poupar capital, desaparecendo, dessa forma, o aparente conflito entre produtividade e emprego. [...] Não se desconhece que podem ocorrer problemas distributivos se a nova tecnologia permite poupar mais mão de obra do que capital. Nesse caso, torna-se necessário aplicar políticas compensatórias - financiadas pelo aumento do produto gerado pela mudança tecnológica - para contrapor aos possíveis efeitos regressivos que poderão ser gerados. ${ }^{14}$

Finalmente, o terceiro eixo do enfoque cepalino é o que se refere aos investimentos em recursos humanos (capacitação, educação, nutrição de gestantes e crianças, saúde, incluindo a infra-estrutura de saneamento). Segundo a Cepal,

[...] e essas ações, em especial os investimentos em educação, ilustram nitidamente a complementariedade entre as medidas tendentes a cumprir com os objetivos de crescimento e eqüidade. O presente enfoque coloca uma ênfase especial na educação e no conhecimento, não só como um serviço social básico, mas como um dos pivôs do progresso técnico. E é por isso que, para conciliar eficiência com eqüidade, torna-se imperativo melhorar a educação e assegurar a todos os estratos sociais um acesso similar a esse serviço. ${ }^{15}$

Justificando e reforçando esse enfoque ou proposta de políticas, FANJZYLBER (1988) recorre às lições da experiência histórica dos Estados Unidos e de países europeus e asiáticos para afirmar que

[...] no mercado internacional a competição não se dá somente entre empresas. Se confrontam também sistemas produtivos, esquemas institucionais e organismos sociais, nos quais a empresa constitui um elemento importante, mas integrado a uma rede de vinculações com o sistema de educação, a infra-estrutura tecnológica, o aparato institucional, as relações gerenciais-trabalhistas, o aparato institucional público e privado, o sistema financeiro etc. Nas nações industrializadas, o debate em torno do aumento da competitividade se dá no marco de instituições cuja legitimidade ninguém questiona. A coesão social é grande. Os padrões de consumo e o acervo de conhecimentos tecnológicos se difundiu e se homogeneizou. A integração produtiva tem como eixo o setor manufatureiro. Em torno do objetivo de aumentar

14 CEPAL, op. cit., p. 18-19.

15 Ibid., p. 19. 
a competitividade, os governos desses países promovem programas de apoio a setores de alto conteúdo tecnológico, reestruturam e valorizam o sistema educativo e de pesquisa e desenvolvimento, levam a cabo programas preferenciais de apoio à pequena e média indústria, criam condições favoráveis à cooperação entre empresas e entre estas e o setor público, promovem reformas do sistema de relações industriais e estudam programas públicos de investimento para o melhoramento da infraestrutura. As empresas, por sua vez, exploram novas formas de vinculação com o sistema acadêmico e com capitais de risco e põem à prova diversas modalidades de relações industriais, como o propósito de estimular a cooperação e a motivação entre os trabalhadores; desenvolvem, ainda, as mais variadas modalidades de cooperação entre elas, com os governos e organismos regionais, especialmente no âmbito da pesquisa e do desenvolvimento. ${ }^{16}$

\section{Segundo FAJNZYLBER (1998),}

[...] estamos assistindo, portanto, a geração de estratégias susceptíveis de serem qualificadas de poskeynesianas. O fenômeno, que está longe de haver se decantado, coexiste com a vigência de uma retórica e de uma praxis de agressivo caráter prekeynesiano. A institucionalidade dos países avançados - que assegura aos distintos atores sociais e políticos o direito de participar ativamente na defesa de suas posições impede que as políticas prekeynesianas inibam o surgimento dessas outras. [...] O mais provável é que a estratégia poskeynesiana configure o marco no qual vai se desenvolver o que fazer econômico nas próximas décadas. ${ }^{17}$

Uma outra versão do conceito de competitividade sistêmica e que conduz a propostas semelhantes de políticas públicas é a formulada pelo Instituto Alemão de Desenvolvimento. De acordo com essa versão, a competitividade sistêmica é o produto da interação complexa e dinâmica de quatro níveis econômicos e sociais: a) o nível micro, o das empresas, que buscam simultaneamente eficiência, qualidade, flexibilidade e rapidez de reação e que contempla fatores tais como a capacidade de gestão, as estratégias empresariais, a gestão da inovação, a integração entre fornecedores, produtores e consumidores, dentre outros; b) o nível meso, correspondente ao Estado e aos atores sociais, que desenvolvem políticas de apoio específicas com vistas à formação de um entorno capaz de fomentar e multiplicar os esforços das empresas (políticas de infra-estrutura física; políticas educacional, de saúde e previdenciária; política tecnológica; política ambiental; política regional etc.); c) o nível macro, que exerce pressões sobre a eficácia das empresas (estabilidade monetária, políticas

16 FAJNZYLBER, op. cit., p. 22-23.

17 Ibid., p. 23. 
fiscal, monetária, cambial, comercial e de regulação da concorrência etc.); e d) o nível meta, que contempla as estruturas básicas de organização jurídica, política e econômica, a capacidade social de organização e de integração e a capacidade dos atores sociais para a coesão social e interação estratégica (ver quadro 2). ${ }^{18}$

\section{Quadro 2 - FATORES DETERMINANTES DA COMPETITIVIDA DE SISTÊMICA SEGUNDO O INSTITU- TO ALEMÃO DE DESENVOLVIMENTO}

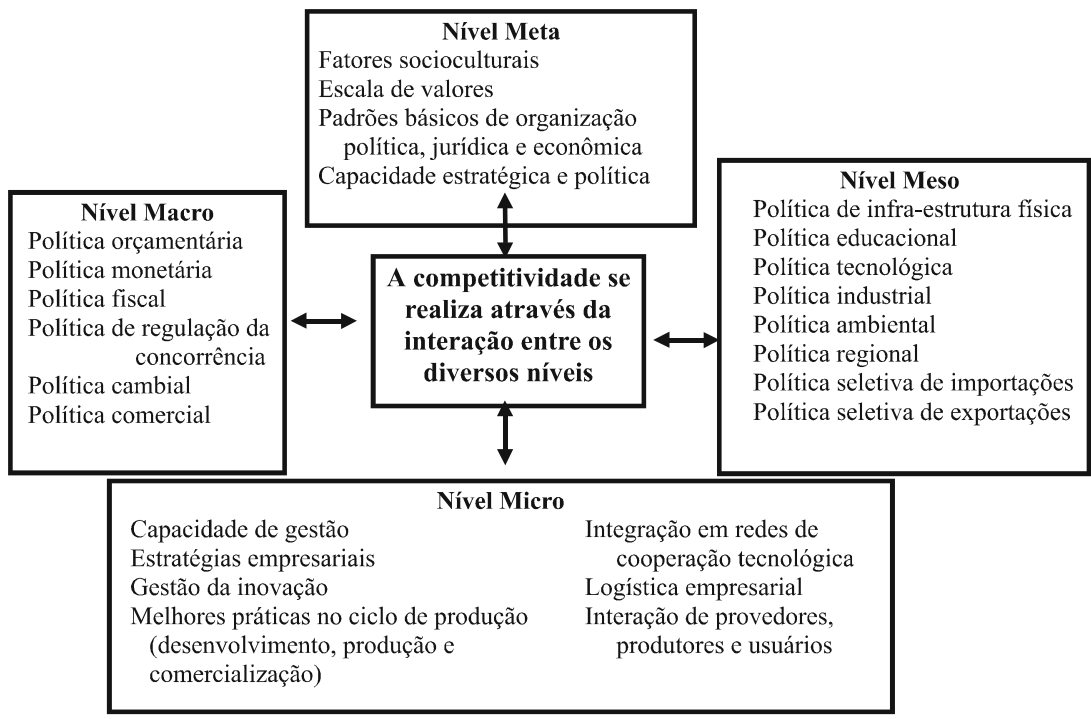

FONTE: ESSER et al. (1996), p. 42.

De acordo com essa concepção, para otimizar a eficiência dos níveis micro, macro e meso, são decisivas, no nível meta,

[...] a capacidade estatal de condução (regulação) da economia e a existência de padrões de organização que permitam mobilizar a capacidade criativa da sociedade. A modernização econômica e o desenvolvimento da competitividade sistêmica não podem alcançar resultados sem a formação de estruturas na sociedade inteira. Se são empreendidas reformas macroeconômicas sem criar, ao mesmo tempo, capacidade de regulação e condução (reforma do Estado, articulação dos atores estratégicos etc.) e sem formar estruturas sociais, as tendências à desintegração social tendem a se agudizar. A competitividade sistêmica

18 Cf. ESSER, K. et al. Competitividade Sistémica: nuevo desafío para las empresas y la política. Revista de la CEPAL, n. 59, ago. 1996. p. 39-52. 
sem integração social é um projeto sem perspectivas. O desenvolvimento da competitividade sistêmica, portanto, é um projeto de transformação social que vai mais além da simples correção dos contextos macro [e microeconômicos]. ${ }^{19}$

Finalmente, no âmbito das teorias recentes sobre o desenvolvimento regional, tem-se o conceito de entorno inovador, com o mesmo sentido analítico e propositivo do conceito de competitividade sistêmica. O conceito de entorno inovador vem sendo considerado como o equivalente dinâmico e socialmente ampliado do conceito de distrito industrial, desenvolvido durante os anos 70 no marco da teoria do crescimento regional endógeno. Ambos os enfoques compartem a idéia de que o desenvolvimento se produz em zonas geográficas concretas, em razão de um complexo conjunto de relações e interações sinérgicas que têm lugar dentro de suas fronteiras, e ressaltam os fatores (internos) do lado da oferta - mas não só os exclusivamente econômicos - como causa do êxito das empresas locais. A novidade desse conceito é que, em lugar de se centrar nos fatores de eficiência das economias locais, nas formas em que as suas estruturas e instituições se organizam em um determinado momento, presta maior atenção nos processos de inovação e de transformação dessas economias. $\mathrm{O}$ conceito do entorno inovador sustenta que este é um microcosmos em que interagem elementos econômicos e sociais (condições de educação, saúde, coesão social, etc.) que implicam em economias externas, de distrito ou de localização e podem, portanto, serem considerados fontes sinérgicas de criação de desenvolvimento econômico. ${ }^{20}$

À luz dessas diferentes versões do conceito de competitividade sistêmica, elevada concentração de renda, atraso educacional e condições precárias de saúde constituem fatores que podem influenciar negativamente as condições de competitividade.

\section{A MODERNA TEORIA DO DESENVOLVIMENTO ECONÔMICO}

A chamada "moderna teoria do desenvolvimento econômico" parte de reformulações ou ampliações de "antigos" modelos que visavam explicar a trajetória e os diferenciais de crescimento econômico entre as nações - a exemplo

19 Cf. ESSER, op. cit., p. 41 - 42.

20 Cf. CUADRADO ROURA, J .R. Planteamientos y teoría sobre el crecimiento regional en Europa en las cuatro últimas décadas. Revista EURE, Santiago, Chile, v. 21, n. 63, p. 23 24, jun. 1995 . 
do modelo de SOLOW (1956) - e procura explicar em que medida as precárias condições sociais vigentes em um determinado país (baixos padrões educacionais, precárias condições de saúde, elevados níveis de pobreza, alto grau de desigualdade etc.) contribuem para restringir o crescimento econômico e os ganhos de produtividade e competitividade.

Como antigamente, essa "moderna teoria" tem por base uma função de produção de padrões clássicos: $\mathrm{Y}=\mathrm{Af}(\mathrm{K}, \mathrm{N})$, onde $\mathrm{Y}$ é o PIB, A é uma medida referente ao padrão tecnológico ou progresso técnico, K é o "capital" e $\mathrm{N}$, a população.

A partir dessa função, "qualquer teoria do crescimento econômico visa, em última instância, explicar como essas variáveis determinam o crescimento do PIB, na seguinte forma: $\mathrm{g}^{\mathrm{Y}}=\mathrm{g}^{\mathrm{A}}+\mathrm{RI}-\alpha \mathrm{g}^{\mathrm{N}}{ }^{\prime} \cdot{ }^{21}$

Nessa equação, $\mathrm{g}^{\mathrm{Y}}$ é a taxa de crescimento per capita do PIB, $\mathrm{g}^{\mathrm{N}}$ e $\mathrm{g}^{\mathrm{A}}$ são as taxas de crescimento da população e do progresso técnico determinadas exogenamente, $\mathrm{R}$ é a produtividade marginal do capital (ou a relação produto/ capital), I é a taxa de investimento (expressa como um percentual do PIB) e $\alpha$ é a participação do capital (K) na renda.

Como pode ser observado, a taxa de crescimento per capita do PIB está positivamente correlacionada com a taxa de crescimento do progresso técnico, com a relação produto/capital e com a taxa de investimento. E está negativamente correlacionada com a taxa de crescimento da população.

As inovações da "moderna teoria do crescimento" referem-se basicamente a ampliar a definição de capital de forma a incluir não só o capital físico, como "antigamente", mas também outros fatores acumuláveis e potencializadores da geração de riqueza, como o capital humano ou conhecimento tecnológico, antes determinados externa ou exogenamente. De certa forma, sob essa nova perspectiva teórica, "I (investimento ou variação do estoque de capital) passa a incluir todos esses e outros fatores acumuláveis (as 'externalidades'), enquanto a definição de progresso técnico exógeno $\left(\mathrm{g}^{\mathrm{A}}\right)$ vai ficando cada vez mais restrita e negligenciável". ${ }^{22}$ Assim, a "moderna teoria do desenvolvimento" acaba por explicar o chamado "resíduo de Solow", endogeneizando na função de produção todos aqueles fatores acumuláveis e potencializadores de riqueza que, antes considerados exógenos ou residuais por SOLOW (1956), agora passam a se

21 PERSOON, T.; TABELLINI, G. Growth, distribution and politics. Washington: IMF Working Paper, 1991. p. 1.

22 Conforme PERSSON e TABELLINI, 1991, op. cit., p. 1. Ver também MANKIW, G.; ROMER, D.; WEIL, D. A contribution to the empirics of economic growth. Quaterly Journal of Economics, v. 107, May 1992. p. 408-409. 
constituir em variáveis importantes para explicar a taxa de crescimento per capita do PIB.

É por isso que essa "moderna teoria" é também chamada de "teoria do crescimento endógeno". É dessa forma também que essa teoria consegue escapar da armadilha dos rendimentos decrescentes, presentes nos "antigos modelos", e explicar porque as taxas de crescimento de alguns países podem crescer, ao longo do tempo, mais do que a de outros países, ampliando - ao invés de fazer convergir - as diferenças de níveis de desenvolvimento econômico e de competitividade entre as nações. ${ }^{23}$ Os "antigos modelos", como o de SOLOW (1956), ${ }^{24}$ na medida em que consideravam o progresso técnico como dado ou exógeno e entendiam o capital somente na sua dimensão física, definiam trajetórias de crescimento sujeitas a rendimentos decrescentes e, portanto, levavam à conclusão de uma possível tendência a um "estado estacionário" e de convergência a longo prazo entre as taxas de crescimento de diferentes países. ${ }^{25}$

$\mathrm{Se}$, nos marcos dessa "moderna teoria", o crescimento da população continuar sendo suposto como determinado exogenamente e, além disso, for considerado que as estatísticas internacionais indicam que a participação do capital na renda $(\alpha)$ - largamente definida - é muito semelhante entre os diversos países, pode-se chegar à conclusão, como o faz essa teoria, de que as razões das diferenças entre as taxas de crescimento econômico dos diversos países são determinadas basicamente pelas diferenças de desempenho com relação a duas variáveis: a taxa de investimento e/ou a produtividade marginal do capital (R) ${ }^{26}$

Assim, é através dessa última variável, entendida a partir de um conceito mais amplo de capital (capital físico + conhecimento tecnológico + capital humano), ${ }^{27}$ que a "moderna teoria do crescimento" vai procurar explicar os impactos das condições sociais sobre o desempenho econômico de um país e ana-

23 ROMER (1986) desenvolve um modelo de crescimento de longo prazo no qual o "conhecimento" (progresso técnico) é assumido como endógeno e o "produto per capita pode crescer sem fronteiras". Nesse modelo, "a taxa de investimento e a taxa de retorno do capital podem crescer, e não decrescer, com o aumento do estoque de capital" (ROMER, P. M. Increasing returns and long-run growth. Journal of Political Economy, v. 94, n. 5, p. 1002-1003, Oct. 1986.). Ver também AZARIADIS, C.; DRAZEN, A. Threshold externalities in economic development. Quaterly Journal of economics, v. 105, p. 501-509, May 1990.

24 Conforme formulado em SOLOW, R. A contribution to the theory of economic growth. Quaterly Jornal of Economics, v. 70, 1956.

25 Ver CORBO, V. Viejas y nuevas teorías de crecimiento: algunos ejemplos para America Latina y Asia Oriental. Pensamiento Ibereamericano (Revista de Economia Política), n. 29, p. 159-161, Ene./Jun. 1996; e AZARIADIS e DRAZEN, op. cit., p. 501-503.

26 Conforme PERSSON e TABELLINI, 1991, op. cit., p. 1.

27 Esses ou outros "fatores acumuláveis e potencializadores da geração de riquezas". 
lisar os vínculos entre a orientação das políticas públicas, o investimento e esse desempenho.

Os modelos mais difundidos dessa teoria são aqueles que explicam como investimentos na acumulação de capital humano, através da educação e de melhorias nas condições de saúde e de nutrição, podem fomentar o crescimento econômico. Esses modelos relacionam uma baixa (alta) taxa de acumulação de capital humano (ou investimentos em educação, capacitação, saúde etc.) e o conseqüente atraso (avanço) educacional e/ou precárias (favoráveis) condições de saúde e nutrição a uma menor (maior) taxa de crescimento econômico.

Nessa perspectiva, BEHRMAN (1996) realiza um exercício que é muito ilustrativo. Esse autor analisa a situação do hiato de escolaridade total dos países da América Latina em relação à experiência internacional e calcula o impacto que um ano a mais de escolaridade (controlada pela renda per capita) poderia ter, no futuro, sobre um conjunto de variáveis econômicas e sociais desses países, dentre as quais a taxa de crescimento econômico, a taxa de crescimento das exportações, a taxa de crescimento da população, as taxas de fecundidade e de natalidade, as taxas de mortalidade infantil, as taxas de analfabetismo e a esperança de vida ao nascer.

Os principais resultados desse exercício são os apresentados na tabela 1. Indicam as taxas de crescimento ou variações estimadas dessas variáveis no futuro para cada ano pelo qual a escolaridade total inicial (em 1965) de países latinoamericanos exceda o nível inicialmente previsto pela sua renda per capita, segundo a experiência ou norma internacional.

Tabela 1 - IMPACTO DE UM ANO A MAIS NA ESCOLARIDADE TOTAL INICIAL (1965) EM PAÍSES DA AMÉRICA LATINA E CARIBE

Taxa média anual de crescimento da renda per capita (1965-1990) $\quad 0,35$

$\begin{array}{lr}\text { Taxa média anual de crescimento das exportações (1980-1990) } & 0,70\end{array}$

Taxa média anual de crescimento da população (1965-1980) $\quad-0,26$

Taxa de fecundidade por mil nascidos vivos (1990) $\quad-0,40$

Taxa de mortalidade infantil por mil nascidos vivos - mulheres (1990) $\quad-8,90$

Taxa de mortalidade infantil abaixo de 5 anos por mil nascidos vivos

$\begin{array}{lr}\text { mulheres (1990) } & -11,80\end{array}$

homens (1990) $\quad-13,40$

Expecativa de vida ao nascer - anos (1990) $\quad 2,00$

Parcela (\%) da população de 0-14 anos (1990) $\quad-2,20$

Parcela (\%) da população de 15-64 anos (1990) $\quad 1,50$

Fonte: BEHRMAN (1996), p. 24. 
Isso significa, por exemplo, que, a médio prazo (cerca de 10/15 anos), a taxa de crescimento da renda per capita tende a ser $0,35 \%$ a.a. mais alta para cada ano pelo qual a escolaridade inicial de países latinoamericanos exceda a norma internacional (ver tabela 1).

Da mesma forma, a médio prazo, a taxa de crescimento das exportações tende a ser $0,7 \%$ a.a. mais alta para cada ano extra na escolaridade inicial, o que demonstraria a importância do avanço educacional para a criação de condições de competitividade internacional.

Por sua vez, também a médio prazo, a taxa de crescimento populacional tende a ser -0,26 menor a.a. para cada ano extra de escolaridade e, no longo prazo (cerca de 25 anos além da situação inicial, em 1990), estima-se que os impactos desse avanço nas demais variáveis demográficas viriam a ser os seguintes: $-0,4$ pontos na taxa de fecundidade; $-8,9$ na taxa de mortalidade infantil (mulheres); -11,8 e -13,4 pontos nas taxas de mortalidade infantil abaixo de 5 anos feminina e masculina, respectivamente; $+2,0$ anos na expectativa de vida ao nascer; $-2,2$ pontos percentuais a menos na parcela da população de 0-14 anos; e $+1,5$ pontos percentuais na parcela da população em idade ativa. Essas tendências acompanham aquelas já mencionadas para o caso da dinâmica demográfica da sociedade brasileira, bem como a análise suas possibilidades enquanto fatores favoráveis ao aumento da competitividade.

A interpretação desses dados apresentados por BERHRMAN (1996), considerando a situação do hiato de escolaridade no Brasil (cerca de 1 ano de atraso em relação à norma internacional), poderia ser feita como a dos possíveis impactos, a médio e longo prazo, nesse conjunto de variáveis, caso viesse a eliminar o seu atraso educacional no curto prazo. ${ }^{28}$

Outros modelos menos difundidos da "moderna teoria do crescimento econômico" vêm realçando o impacto desfavorável de um elevado nível de desigualdade da distribuição de renda ou da propriedade sobre as taxas de crescimento econômico.

Um desses modelos é o de GALOR e ZEIRA (1993). No longo prazo, como existem indivisibilidades nos investimentos em capital humano, o crescimento é afetado negativamente pela distribuição inicial da riqueza, ou mais especificamente, pela percentagem de indivíduos cujas dotações de recursos são suficientemente grandes para torná-los aptos a investir em capital humano. Dada a trajetória de ajustes de uma economia a inovações tecnológicas, em países onde essa distribuição é menos desigual, os aumentos nos salários da

28 Cf. BARROS, R.; MENDONÇA, R. Investimento em educação e desenvolvimento econômico. Rio de Janeiro: IPEA, 1997. (Texto de Discussão, n. 25) p. 5. 
mão-de-obra qualificada atraem um maior número de indivíduos a investir em capital humano, já que possuem riqueza suficiente para tal. Ao contrário, em países relativamente pobres, onde a distribuição de riquezas é fortemente desigual, os investimentos em capital humano não tenderão a aumentar expressivamente, já que uma elevada proporção de indivíduos não possui recursos suficientes para financiá-los e, portanto, os benefícios econômicos da inovação serão limitados. Segundo esses autores, "os resultados dos seus estudos podem ser sintetizados como a descrição da importância da existência de uma classe média para acicatar o crescimento econômico". ${ }^{29}$

Outro modelo que correlaciona negativamente desigualdade na distribuição de renda e taxa de crescimento econômico é o de PERSSON e TABELLINI (1991). ${ }^{30}$ Esses autores partem do princípio de que a chave para o entendimento das diferenças no crescimento e de competividade entre as nações refere-se às diferentes formas pelas quais as políticas públicas afetam a taxa de investimento, ou seja, a acumulação de capital físico, de capital humano e/ou de conhecimentos tecnológicos passíveis de serem incorporados aos processos de produção. Consideram que, para entender essas diferentes formas, é necessário conhecer como as instituições políticas incorporam ou agregam, na orientação das políticas públicas, os conflitos de interesses existentes na sociedade.

A idéia básica desse modelo é a de que quanto maior a desigualdade seja na distribuição pessoal da renda, seja na parcela de renda que é apropriada pelos diferentes fatores de produção - maior é a pressão por políticas redistributivas. Essa maior pressão por esse tipo de política induz a menores incentivos para a acumulação de capital e, portanto, implica em uma menor taxa de crescimento econômico.

Uma das versões do modelo desses autores estipula que, em sociedades democráticas, quanto maior a desigualdade, menores serão os investimentos, na medida que os impostos tenderão a ser mais elevados, já que as suas taxas estarão relacionadas às preferências do eleitor mediano. Quanto mais baixa a renda mediana em relação à renda média, maiores serão as pressões redistributivas e maiores tenderão a ser as taxas de impostos de equilíbrio. ${ }^{31}$

29 Cf. GALOR, O.; ZEIRA, J. Income distribution and macroeconomics. Review of Economic Studies, v. 60 (1), n. 202, p. 51, Jan. 1993.

30 Ver também PERSSON, T.; TABELLINI, G. Is inequality haemful for growth? The American Economic Review, June 1994.

31 Um outro modelo de semelhante a esse foi desenvolvido por PEROTTI, R. Political equilibrium, income distribution and growth. The Review of Economic Studies, v. 60 (4), n. 205, Oct. 1993. 


\section{CONCLUSÕES}

Como pode ser observado, embora formuladas por concepções conceituais muito diferentes, as idéias e as propostas de políticas vinculadas ao conceito de competitividade sistêmica e à "moderna teroria do crescimento econômico" são muito semelhantes e convergentes. Afirmam que condições sociais precárias (grandes desigualdades na distribuição de renda, atraso educacional etc.) constituem fatores que podem limitar o crescimento econômico, a expansão da produtividade (PIB per capita) e, portanto, as possibilidades de competitividade internacional de um país.

A explicação do "resíduo de Solow" pela "moderna teoria do desenvolvimento" - endogeneizando na função de produção todos aqueles acumuláveis e potencializadores de riqueza (fatores estritamente econômicos ou não), antes considerados exógenos ou residuais por Solow - leva, como nas concepções relativas à competitividade sistêmica, a um amplo leque de variáveis econômicas e sociais como determinante de fundamental importância na explicação da taxa de crescimento per capita do PIB.

Mais ainda, essas concepções teóricas também escapam da armadilha dos rendimentos decrescentes, presentes nos "antigos modelos", e explicam porque as taxas de crescimento de alguns países podem crescer, ao longo do tempo, mais do que a de outros países, ampliando - ao invés de fazer convergir, pela liberdade dos mercados e mobilidade dos fatores - as diferenças de níveis de desenvolvimento econômico e de competitividade entre as nações.

E, finalmente, resgatam, nesse contexto, a importância do papel do Estado e das políticas públicas na medida que a promoção das condições sociais necessárias para ampliar as possibilidades de crescimento econômico vão muito além das determinações correntes do livre jogo das "leis de mercado".

\section{RESUMO}

O objetivo desse artigo é mostrar que as idéias e as propostas de políticas vinculadas ao conceito de competitividade sistêmica e à "moderna teoria do crescimento econômico" são muito semelhantes e convergentes.

Tanto esse conceito quanto essa teoria afirmam que condições sociais precárias (grandes desigualdades na distribuição de renda, atraso educacional, etc.) constituem fatores que podem limitar o crescimento econômico, a expansão da produtividade (PIB per capita) e, portanto, as possibilidades de competitividade internacional de um País.

A explicação do "resíduo de Solow" pela "moderna teoria do desenvolvimento" - endogeneizando na função de produção todos aqueles fatores 
acumuláveis e potencializadores de riqueza (estritamente econômicos ou não), antes considerados exógenos ou residuais por Solow - leva, como nas concepções relativas à competitividade sistêmica, a um amplo leque de variáveis economicas e sociais como determinante de fundamental importância na explicação da taxa de crescimento per capita do PIB.

Essas concepções teóricas também escapam da armadilha dos rendimentos decrescente, presentes nos "antigos modelos", e explicam porque as taxas de crescimento de alguns países podem crescer, ao longo do tempo, mais do que a de outros países, ampliando - ao invés de fazer convergir, pela liberdade dos mercados e mobilidade dos fatores - as diferenças de níveis de desenvolvimento econômico e de competitividade entre as Nações.

\begin{abstract}
The objective of this article is to show that the ideas and the political proposals tied to the concept of sistemic competitiveness and the "modern theory of the economic growth" are very similar and convergent.

Both the concept and the theory affirm that precarious social conditions (great inequalities in the income distribution, educational delay, etc.) constitute factors that can limit the economic growth, the expansion of productivity (the GDP per capita) and, therefore, the possibilities of international competitiveness of a Country.

The explanation of the "Solow's residue" for the "modern theory of the development" - internalized in the production function all those factors that improve the wealth (strictly economic or not), before considered external or vestigial for Solow - leads, as in the conceptions related to the sistemic competitiveness, to an ample fan of economic and social variables as determinants of basic importance in the explanation of the per capita tax growth of the GIP per capita.

These theoretical conceptions also escape of the the incomes decreasing trap, found in the "old models", and explain why the growth rates of some countries can grow, along the time, more than other countries, extending - instead of making to it converge, through the freedom of the markets and mobility of the factors - differences of levels of economic development and competitiveness between the Nations.
\end{abstract}




\section{REFERÊNCIAS}

AZARIADIS, C.; DRAZEN, A. Threshold externalities in economic development. Quartely Journal of Economics, v. 105, May 1990.

BARROS, Ricardo P.; MENDONÇA, Rosane. Investimento em educação e desenvolvimento econômico. Rio de Janeiro: IPEA, 1997. (Texto de Discussão, n. 525).

BEHRMAN, Jere R. Human resources in Latin America and the Caribe. Washington: BID, 1996.

BID. Progresso socioeconômico na América Latina: relatório 1993 (parte especial: recursos humanos). Washington D.C., 1993.

CEPAL. Anuario + Estadístico de América Latina y el Caribe 1996. Chile: Nações Unidas, 1997.

CEPAL. Equidad y transformación productiva: un enfoque integrado. Santiago do Chile: CEPAL, 1992.

CORBO, Vittorio. Viejas y nuevas teorías de crecimiento: algunos ejemplos para América Latina y Asia Oriental. Pensamiento Iberoamericano (Revista de Economía Política), n. 29, ene./Jun. 1996.

CUADRADO ROURA, J. R. Planteamientos y teorías sobre el crecimiento regional en Europa en las cuatro últimas décadas. Revista EURE, Santiago, Chile, v. 21, n. 63, Jun. 1995.

ESSER, K. et al. Competitividad sistémica: nuevo desafío para las empresas y la política. Revista de la CEPAL, Santiago, Chile, n. 59, ago. 1996.

FAJNZYLBER, Fernando. Competitividad internacional: evolución y lecciones. Revista de la CEPAL, Santiago, Chile, n. 36, dic. 1988.

FDC. Estudo sobre o Brasil na competitividade mundial 1996. Belo Horizonte: Fundação Dom Cabral, 1996.

GALOR, O.; ZEIRA, J. Income distribution and macroeconomics. The Review of Economic Studies, v. 60 (1), n. 202, Jan. 1993.

MANKIW, G.; ROMER, D.; WEIL, D. A contribution to the empirics of economic growth. Quartely Journal of Economics, v. 107, May 1992.

PERSSON, Torsten; TABELLINI, Guido. Growth, distribution and politics. Washington: IMF Working Paper, 1991.

PERSSON, Torsten; TABELLINI, Guido. Is inequality harmful for growth? The American Economic Review, June 1994.

PEROTTI, R. Political equilibrium, income distribution and growth. The Review of Economic Studies, v. 60 (4), n. 205, Oct. 1993.

ROMER, Paul M. Increasing returns and long-run growth. Journal of Political Economy, v. 94, n. 5, Oct. 1986. 
MACEDO, M. de M. Condições sociais e competitividade

SERRA, José. A reconcentração da renda: justificações, explicações, dúvidas. In: TOLIPAN, R.; TINELLI, A. C. A controvérsia sobre distribuição de renda e desenvolvimento. Rio de Janeiro: Zahar, 1975.

SOLOW, R. A contribution to the theory of economic growth. Quartely Journal of Economics, v. 70, 1956.

TAUILE, José R. Novos padrões tecnológicos, competitividade e bem-estar social: perspectivas brasileiras. Rio de Janeiro: IEI/UFRJ, 1988. 